\title{
Enhancing transglutaminase production of Streptomyces mobaraensis by iterative mutagenesis breeding with atmospheric and room-temperature plasma (ARTP)
}

Ying Jiang ${ }^{1} \mathbb{D}$, Yue-Peng Shang ${ }^{1}$, Hao Li ${ }^{1}$, Chao Zhang ${ }^{1}$, Jiang Pan ${ }^{1}$, Yun-Peng Bai ${ }^{1}$, Chun-Xiu Li ${ }^{1 *}$ and Jian-He Xu ${ }^{1,2^{*}}$

\begin{abstract}
Objectives: To improve the fermentation production of transglutaminase (TGase) from Streptomyces mobaraensis for applications in the food industry, the atmospheric and room-temperature plasma (ARTP) mutagenesis was applied to breed S. mobaraensis mutants with increased TGase production.

Results: After eight rounds of iterative ARTP mutagenesis, four genetically stable mutants, Sm5-V1, Sm6-V13, Sm2V10, and Sm7-V12, were identified, which showed increased TGase production by 27, 24, 24, and 19\%, respectively. The best mutant Sm5-V1 exhibited a maximum TGase activity of $5.85 \mathrm{U} / \mathrm{mL}$ during flask fermentation. Compared to the wild-type strain, the transcription levels of the zymogen TGase genes in the mutants increased significantly as indicated by quantitative real-time PCR, while the gene nucleotide sequences of the mutants did not change at all. It was shown that the overexpression of TGase zymogen gene in the mutants contributes to the increase in TGase production.
\end{abstract}

Conclusions: ARTP is a potentially efficient tool for microbial mutation breeding to bring some significant changes required for the industrial applications.

Keywords: Atmospheric and room-temperature plasma, Breeding, Streptomyces mobaraensis, Transcription level, Transglutaminase

\section{Background}

Transglutaminases (TGase, EC 2.3.2.13), also referred to protein-glutamine $\gamma$-glutamyltransferases, are enzymes capable of catalyzing acyl-transfer reactions between the $\gamma$-carboxamide group of protein or peptide-bound glutamine and $\varepsilon$-amino group of lysine or other primary amines (Zhu et al. 1995; Martins et al. 2014). The covalent modifications of proteins promoted by TGase facilitate extensive applications in food, medicine, and other industries. TGases are widely distributed in prokaryotes and eukaryotes. TGases from animal tissues are $\mathrm{Ca}^{2+}$-dependent enzymes that lead to the precipitation

\footnotetext{
*Correspondence: chunxiuli@ecust.edu.cn; jianhexu@ecust.edu.cn 1 State Key Laboratory of Bioreactor Engineering, East China University of Science and Technology, Shanghai 200237, People's Republic of China Full list of author information is available at the end of the article
}

of proteins from food containing casein, soybean globulin, or myosin (Martins et al. 2014). However, the scarcity of resources as well as complexity of further extraction and purification still limits their applications. Microbial transglutaminases (MTG) that were usually found in Streptomyces (Duran et al. 1998; Marx et al. 2008) and Bacillus (Kobayashi et al. 1998; Soares et al. 2003) species have a wider application due to their advantages as $\mathrm{Ca}^{2+}$-independent activity, thermostability, and broad specificity for acyl donors (Salis et al. 2015). Up to now, MTG for applications in the food processing were mainly produced by fermentation of Streptomyces mobaraensis (Yokoyama et al. 2004). TGase from S. mobaraensis was known to be secreted as a zymogen and then activated by proteolytic processing to the enzymatically active mature form (Zotzel et al. 2003a, b). Its pro-region is essential for 
efficient protein folding, secretion, and suppression of the enzymatic activity (Yurimoto et al. 2004). Considering the fact that genetically engineered strains are somehow restricted in the food industry, it is more feasible to improve TGase production by mutation breeding.

Microbial mutation breeding by altering the genomes shows great significance for biotechnology researches and applications (Tan et al. 2014; Kumar 2015). Recently, a novel and efficient mutation tool called atmospheric and room-temperature plasma (ARTP) has been successfully employed to cause some significant changes in enzyme activity, biochemical productivity, and metabolism without lethal damages (Guo et al. 2011; Lu et al. 2011; Xu et al. 2012; Wang et al. 2014). Compared to the conventional mutation breeding methods, ARTP mutagenesis shows some distinct advantages, such as low costs, low and controllable plasma temperatures, various active chemical species with a high density, rapid mutation, flexible and secure operations (Laroussi 2005; Zhang et al. 2014, 2015).

In this study, the iterative ARTP mutagenesis was applied to $S$. mobaraensis for breeding mutants with increased TGase production. Protocols for iterative rapid mutation of $S$. mobaraensis with helium-driven ARTP system and effective tube screening method of the mutants were established. The transcription levels and the nucleotide sequences of the gene (pro-smtg) encoding TGase zymogen were compared between the mutants and the wild-type strain to explain the reasons for the enhanced TGase production, which may provide a valuable guidance for further researches on mechanisms regarding ARTP effects on the whole cells and the intracellular bio-macromolecules.

\section{Methods}

\section{Materials}

L-glutamic acid $\gamma$-monohydroxamate was purchased from Sigma-Aldrich Co., Ltd. (Shanghai, China). $N-\alpha-$

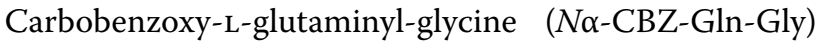
was purchased from Civi Chemical Technology Co., Ltd. (Shanghai, China). Reduced glutathione was purchased from Aladdin Reagent Co., Ltd. (Shanghai, China). Allin-One First-Strand cDNA Synthesis SuperMix (OneStep gDNA Removal) and TransStart Tip Green qPCR SuperMix that were used for RT-PCR (Reverse Transcription PCR) and qRT-PCR (quantitative Real-Time PCR) were purchased from TransBionovo Co., Ltd. (Beijing, China). All other reagents were obtained from commercial sources and were of analytical grade.

\section{Strains and media}

Escherichia coli DH5 $\alpha$ was used as the host strain for the recombinant DNA manipulations. Streptomyces mobaraensis, the wild-type strain ( $S$. mobaraensis ECU7480, stored in our lab) and the mutants generated by ARTP mutagenesis, were grown on a solid medium comprising $20 \mathrm{~g} / \mathrm{L}$ soluble starch, $3 \mathrm{~g} / \mathrm{L}$ tryptone, $1 \mathrm{~g} / \mathrm{L}$ $\mathrm{KNO}_{3}, 0.5 \mathrm{~g} / \mathrm{L} \quad \mathrm{K}_{2} \mathrm{HPO}_{4} \cdot 3 \mathrm{H}_{2} \mathrm{O}, 0.5 \mathrm{~g} / \mathrm{L} \mathrm{MgSO}_{4} \cdot 7 \mathrm{H}_{2} \mathrm{O}$, $0.5 \mathrm{~g} / \mathrm{L} \mathrm{NaCl}, 0.01 \mathrm{~g} / \mathrm{L} \mathrm{FeSO}_{4} \cdot 7 \mathrm{H}_{2} \mathrm{O}$, and $1.5-2.0 \%(\mathrm{w} / \mathrm{v})$ agar at $\mathrm{pH} 7.4-7.6$ and $30{ }^{\circ} \mathrm{C}$ for 5 days. Both tube and flask fermentations were conducted using a seeding medium $(20 \mathrm{~g} / \mathrm{L}$ glycerol, $20 \mathrm{~g} / \mathrm{L}$ tryptone, $5 \mathrm{~g} / \mathrm{L}$ yeast extract, $2 \mathrm{~g} / \mathrm{L} \quad \mathrm{MgSO}_{4} \cdot 7 \mathrm{H}_{2} \mathrm{O}, 2.62 \mathrm{~g} / \mathrm{L} \mathrm{K}_{2} \mathrm{HPO}_{4} \cdot 3 \mathrm{H}_{2} \mathrm{O}$, $2 \mathrm{~g} / \mathrm{L} \mathrm{KH}_{2} \mathrm{PO}_{4}, \mathrm{pH} 7.0$ ) at $30{ }^{\circ} \mathrm{C}$ for $24 \mathrm{~h}$ to prepare the inoculums and a fermentation medium $(20 \mathrm{~g} / \mathrm{L}$ glycerol, $20 \mathrm{~g} / \mathrm{L}$ tryptone, $5.5 \mathrm{~g} / \mathrm{L}$ corn steep powder, $5 \mathrm{~g} / \mathrm{L}$ yeast extract, $2 \mathrm{~g} / \mathrm{L} \mathrm{MgSO}_{4}, 2.62 \mathrm{~g} / \mathrm{L} \mathrm{K}_{2} \mathrm{HPO}_{4} \cdot 3 \mathrm{H}_{2} \mathrm{O}, 10 \mathrm{~g} / \mathrm{L}$ $\mathrm{CaCO}_{3}, \mathrm{pH} 7.2$ ) at $30{ }^{\circ} \mathrm{C}$ with $8-10 \%$ inoculum size for the production of TGase.

\section{Procedures for iterative mutagenesis with ARTP and directed screening}

The procedures for iterative mutation of $S$. mobaraensis genome with ARTP mutation breeding system purchased from Si Qing Yuan Biotechnology Co., Ltd. (Beijing, China) and the following screening are shown in Fig. 1. In this study, pure helium was used as the working gas at a flow rate of $10 \mathrm{slpm}$ (standard liters per minute). The RF power input was $40 \mathrm{~W}$. The distance $(D)$ between the plasma torch nozzle exit and the sample plate was $4 \mathrm{~mm}$ and the plasma jet temperature was below $30{ }^{\circ} \mathrm{C}$. To provide different dosages of the active species in the plasma jet region, $10 \mu \mathrm{L}$ of the spore suspension was pipetted onto the stainless minidisk and then exposed to ARTP jet for different treatment times ranging from 10 to $60 \mathrm{~s}$. Spores without treatment were used as the control.

After ARTP mutation, the spore suspension was transferred onto solid medium. Single colonies from the solid medium were selected randomly and inoculated into a test tube containing $3 \mathrm{~mL}$ fermentation medium for $96 \mathrm{~h}$ fermentation. The cell-free supernatant of fermentation broth was withdrawn for TGase activity detection. The top eight mutants with increased TGase production were chosen as the starting strains for the next round of ARTP mutagenesis. After eight rounds of iterative ARTP mutagenesis, flask cultivation was performed to verify the TGase production of selected mutants from shake tube screening. The selected mutants grown on the solid medium were cultivated in $250-\mathrm{mL}$ flasks containing $25 \mathrm{~mL}$ seeding medium at $30{ }^{\circ} \mathrm{C}$ for $24 \mathrm{~h}$. Then, $2.5 \mathrm{~mL}$ of the seeding culture was transferred into 250 $\mathrm{mL}$ shake flasks containing $25 \mathrm{~mL}$ fermentation medium and cultured at $30{ }^{\circ} \mathrm{C}$. Aliquots of the cell-free supernatant were taken at different time intervals for examination of the TGase activity. Additionally, the genetic stability of the identified mutants was evaluated by eight rounds 


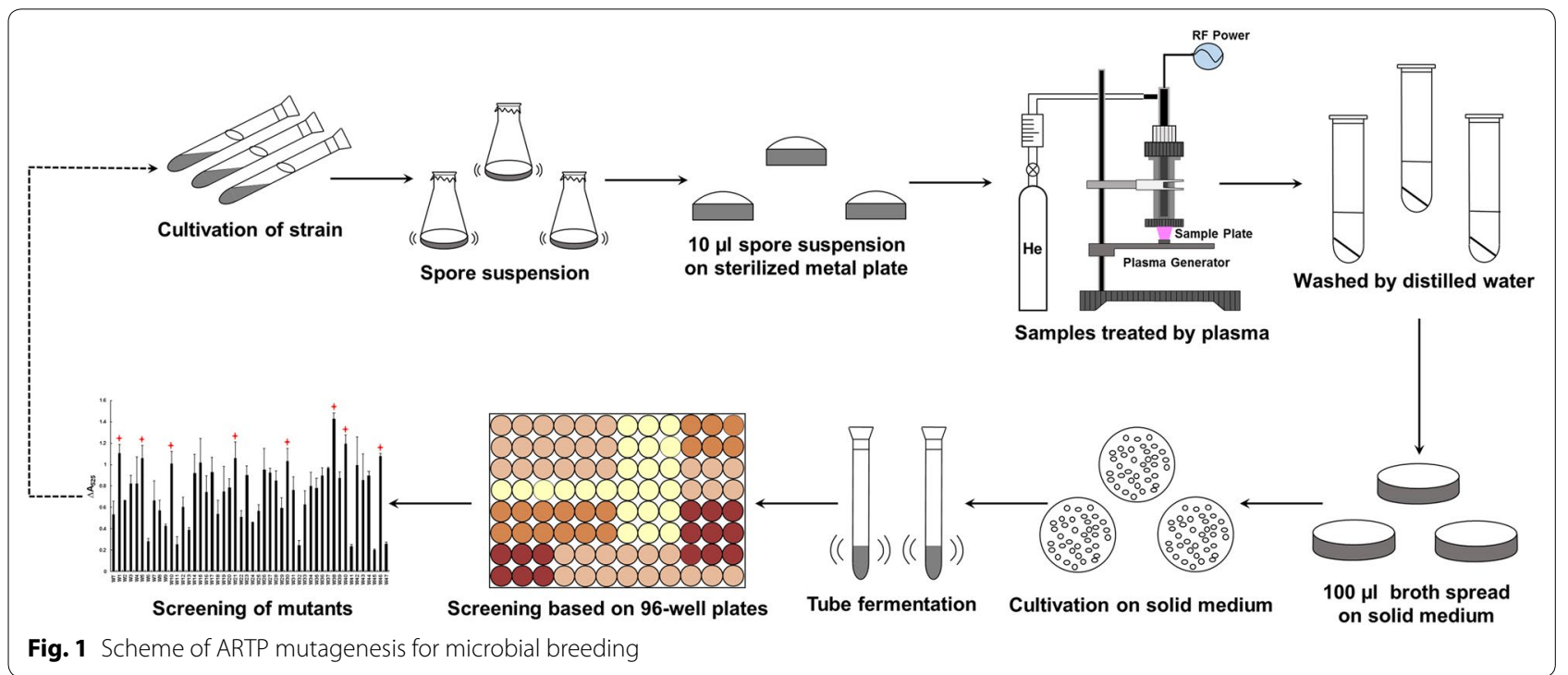

of subcultures. The TGase production of the mutants was examined by shake flask fermentation in every two subcultures.

\section{Evaluation of ARTP mutagenesis of S. mobaraensis}

The lethal rates of the spores under different treatment times were evaluated according to Eq. 1. The mutation rate and the positive mutation rate were calculated based on Eqs. 2 and 3, respectively.

$$
\begin{aligned}
& \text { Lethal rate }(\%)=\frac{U-T}{U} \times 100 \\
& \text { Mutation rate }\left(R_{\mathrm{M}}\right)(\%)=\frac{M}{T} \times 100 \\
& \text { Positive mutation rate }\left(R_{\mathrm{P}}\right)(\%)=\frac{P}{M} \times 100,
\end{aligned}
$$

where $U$ is the total colony count of the sample without treatment, $T$ is the total colony count after treatment with ARTP, $M$ is the total colony count of mutants with different TGase production from the wild-type strain, and $P$ is the total colony count of mutants with increased TGase production than that of the wild-type strain. All the colony numbers were obtained by the colony forming unit (CFU) method on a solid medium.

\section{Activity assay of TGase}

The activity of TGase was measured according to the colorimetric hydroxamate procedure (Grossowicz et al. 1950) using $N \alpha-C B Z-G l n-G l y$ as the substrate. The calibration curve was prepared using L-glutamic acid $\gamma$-monohydroxamic acid as a standard. One unit (U) of TGase activity was defined as the amount of enzyme that catalyzes the formation of $1 \mu \mathrm{mol} \mathrm{L}$-glutamic acid $\gamma$-monohydroxamate per minute at $37^{\circ} \mathrm{C}$.

\section{Quantitative real-time PCR analysis}

Total RNAs of $S$. mobaraensis ECU7480 and its mutants were extracted after cultivation for different times. The mycelium pellets were collected by centrifugation and then frozen in liquid nitrogen immediately. The extraction of total RNAs was performed using the SV Total RNA Isolation System (Promega, USA) according to the manufacturer's protocol. The quantity and quality of the isolated RNAs were examined by NanoDrop 2000c UVVis spectrophotometer (Thermo Scientific, USA) and agarose gel electrophoresis. Subsequently, the reverse transcription PCR (RT-PCR) was carried out using $1 \mu \mathrm{g}$ total RNA as the template. The gene transcription level of pro-smtg during fermentation process was investigated by quantitative real-time PCR (qRT-PCR) with primers listed in Table 1. The qRT-PCR reaction consisted of an initial denaturation at $94{ }^{\circ} \mathrm{C}$ and 40 amplifications cycles of $5 \mathrm{~s}$ at $94{ }^{\circ} \mathrm{C}$ and $60 \mathrm{~s}$ at $64^{\circ} \mathrm{C}$. The target gene transcription level was normalized internally to that of $16 \mathrm{~S}$ rRNA gene for its transcription during overall growth stages was relatively stable.

\section{Cloning of pro-smtg gene from S. mobaraensis mutants}

Genomic DNAs were obtained from S. mobaraensis mutants and the wild-type strain. The primers used for the PCR are listed in Table 1. The PCR procedure was set as follows: $\left(95{ }^{\circ} \mathrm{C}, 5 \mathrm{~min}\right) 1 \mathrm{cycle}$; $\left(94{ }^{\circ} \mathrm{C}, 1 \mathrm{~min} ; 65^{\circ} \mathrm{C}\right.$, $\left.30 \mathrm{~s} ; 72{ }^{\circ} \mathrm{C}, 90 \mathrm{~s}\right) 30$ cycles; and $\left(72{ }^{\circ} \mathrm{C}, 10 \mathrm{~min}\right) 1$ cycle. The amplified PCR products (1200 bp) were ligated into 
Table 1 Primers used in this study

\begin{tabular}{lll}
\hline Name & Sequences $\left(\mathbf{5}^{\prime} \mathbf{- 3} \mathbf{3}^{\prime}\right)$ & Application \\
\hline 16S rRNA_L1 & AGCAGCGGAGCATGTGGCTT & 16S rRNA gene transcription \\
16S rRNA_R1 & TGCGCTCGTTGCGGGACTTA & \\
pro-smtg-L1 & CATGTCGAGGGACAGGAACA & pro-smtg gene transcription \\
pro-smtg-R1 & TTGCGGAACTTGCTCTCGTA & \\
pro-smtg-FP & CGGAATTCATGCCGTCCGC & pro-smtg gene amplification \\
pro-smtg-RP & CCCGC & \\
& CCCTG & \\
\hline
\end{tabular}

plasmid pMD-19T and sequenced for alignment to that of the wild-type strain.

\section{Results and discussion}

\section{Mutation and screening of the mutants}

A well-controlled lethal rate is fundamental for effective mutation and screening of the mutants. The lethal rates of $S$. mobaraensis with respect to various treatment times are shown in Fig. 2, which indicated that the lethal rate increased to $66.5,93.1$, and $99.2 \%$, respectively, after treated for 30,40 , and $50 \mathrm{~s}$. When the samples were treated for $50 \mathrm{~s}$ or even longer, no spores could survive. According to previous reports (Guo et al. 2011; Hua et al. 2010 ), a lethal rate of $90 \%$ was considered appropriate. Besides, keeping the lethal rate high is necessary for the effective mutation and selection of mutant strains. Therefore, the ARTP treatment time applied in this study was determined as $40 \mathrm{~s}$.

After eight rounds of iterative ARTP mutagenesis, 501 mutants in total were selected for tube-fermentation screening, as shown in Additional file 1: Figure S1. To investigate the accumulative effect on TGase production by iterative ARTP mutagenesis, the mutation and screening results for each round were collected and compared.

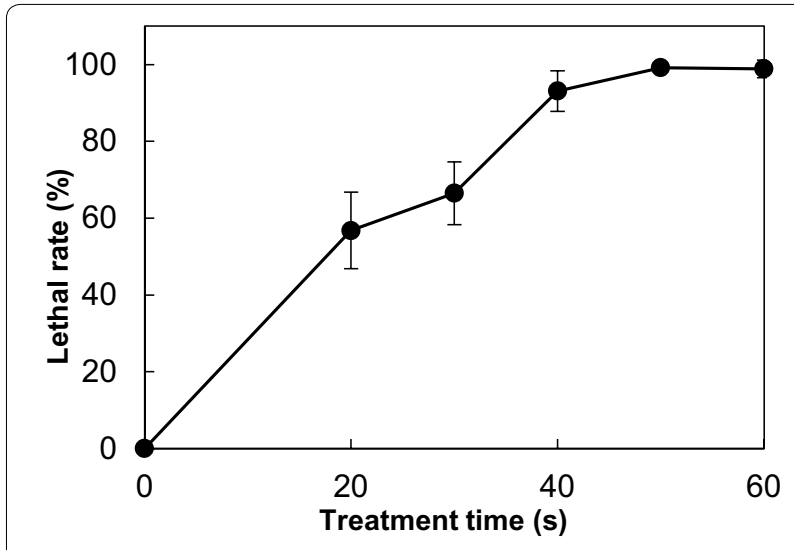

Fig. 2 Lethal rate of S. mobaraensis by ARTP mutagenesis
The statistic results shown in Table 2 and Fig. 3 indicated that the proportion of positive mutants was scaled up with the increase of iterative rounds. Moreover, the TGase production of the best mutant for each round presented a fluctuant improving trend. Thus, the increase of iterative rounds might exhibit an accumulative effect on TGase production of the mutants.

\section{TGase production of the mutants}

Shake flask fermentation was conducted to verify the potentially positive mutants identified in the tube fermentation. Finally, four mutants, Sm5-V1, Sm6-V13, $S m 2-V 10$, and $S m 7-V 12$, were identified in the ARTP breeding process, and the TGase production of these mutants is shown in Table 3 . The highest TGase production reached $5.85 \mathrm{U} / \mathrm{mL}$, which represented a $27 \%$ increase as compared with the wild-type strain.

The genetic stability is one of the key performance factors for a promising industrial strain because it reflects

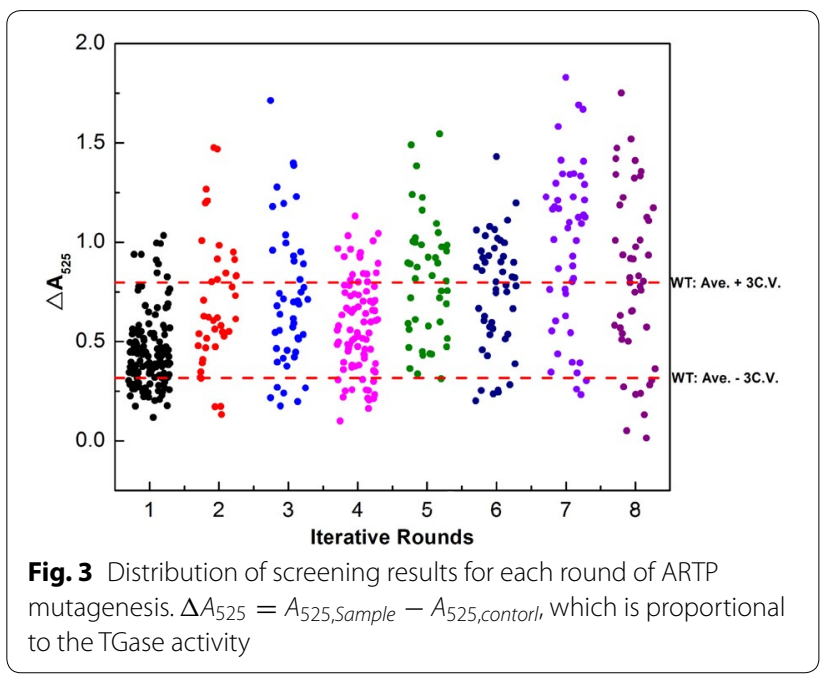

Table 2 Mutation and screening results for each round of ARTP mutagenesis

\begin{tabular}{llll}
\hline Iterative round & $\boldsymbol{R}_{\mathbf{M}}(\%)$ & $\boldsymbol{R}_{\mathbf{P}}(\%)$ & Average $\boldsymbol{\Delta} \boldsymbol{A}_{\mathbf{5 2 5}}$ of mutants \\
\hline WT & - & - & $0.56 \pm 0.08$ \\
1 & 32.1 & 6.4 & $0.44 \pm 0.19$ \\
2 & 48.8 & 36.6 & $0.69 \pm 0.33$ \\
3 & 45.7 & 32.6 & $0.71 \pm 0.35$ \\
4 & 34.8 & 19.1 & $0.58 \pm 0.23$ \\
5 & 56.8 & 54.6 & $0.81 \pm 0.31$ \\
6 & 62.5 & 50.0 & $0.75 \pm 0.28$ \\
7 & 74.5 & 68.1 & $0.98 \pm 0.41$ \\
8 & 69.6 & 52.2 & $0.83 \pm 0.43$ \\
\hline
\end{tabular}


Table 3 TGase production of S. mobaraensis wild-type and ARTP mutants

\begin{tabular}{lll}
\hline Strain & TGase titer $(\mathbf{U} / \mathbf{m L})$ & Relative production $(\%)$ \\
\hline WT & $4.60 \pm 0.17$ & $100 \pm 4$ \\
Sm5-V1 & $5.85 \pm 0.21$ & $127 \pm 5$ \\
Sm6-V13 & $5.72 \pm 0.16$ & $124 \pm 4$ \\
Sm2-V10 & $5.68 \pm 0.19$ & $124 \pm 4$ \\
Sm7-V12 & $5.49 \pm 0.13$ & $119 \pm 3$ \\
\hline
\end{tabular}

the potential mutations at the gene level (Ren et al. 2017). The genetic stability test results shown in Additional file 1:Figure $\mathrm{S} 2$ indicated that the TGase production of the identified mutants still remained stable after eight rounds of subcultures. These results proved that ARTP mutagenesis is a promising mutation breeding tool for industrial applications.
Pro-smtg gene expression level of the wild-type and mutant strains

The enhanced TGase production caused by ARTP mutagenesis may be attributed to two effects. A direct effect will happen if the structural gene (pro-smtg) of TGase zymogen is altered, leading to the change in the specific activity of the protein. Indirect effect happens when the relevant genes regulating the expression of TGase zymogen are altered.

Firstly, the pro-smtg gene nucleotide sequences of the four mutants showed no differences from the original sequence of the native enzyme from the wild-type strain, as indicated by gene cloning and sequence alignment shown in Additional file 1: Figure S3. However, qRT-PCR results shown in Fig. 4 indicated that the prosmtg expression levels of the four mutants were remarkably improved as compared to that of the parental strain, which might lead to the increase in TGase production. The analysis from transcription level conducted in this
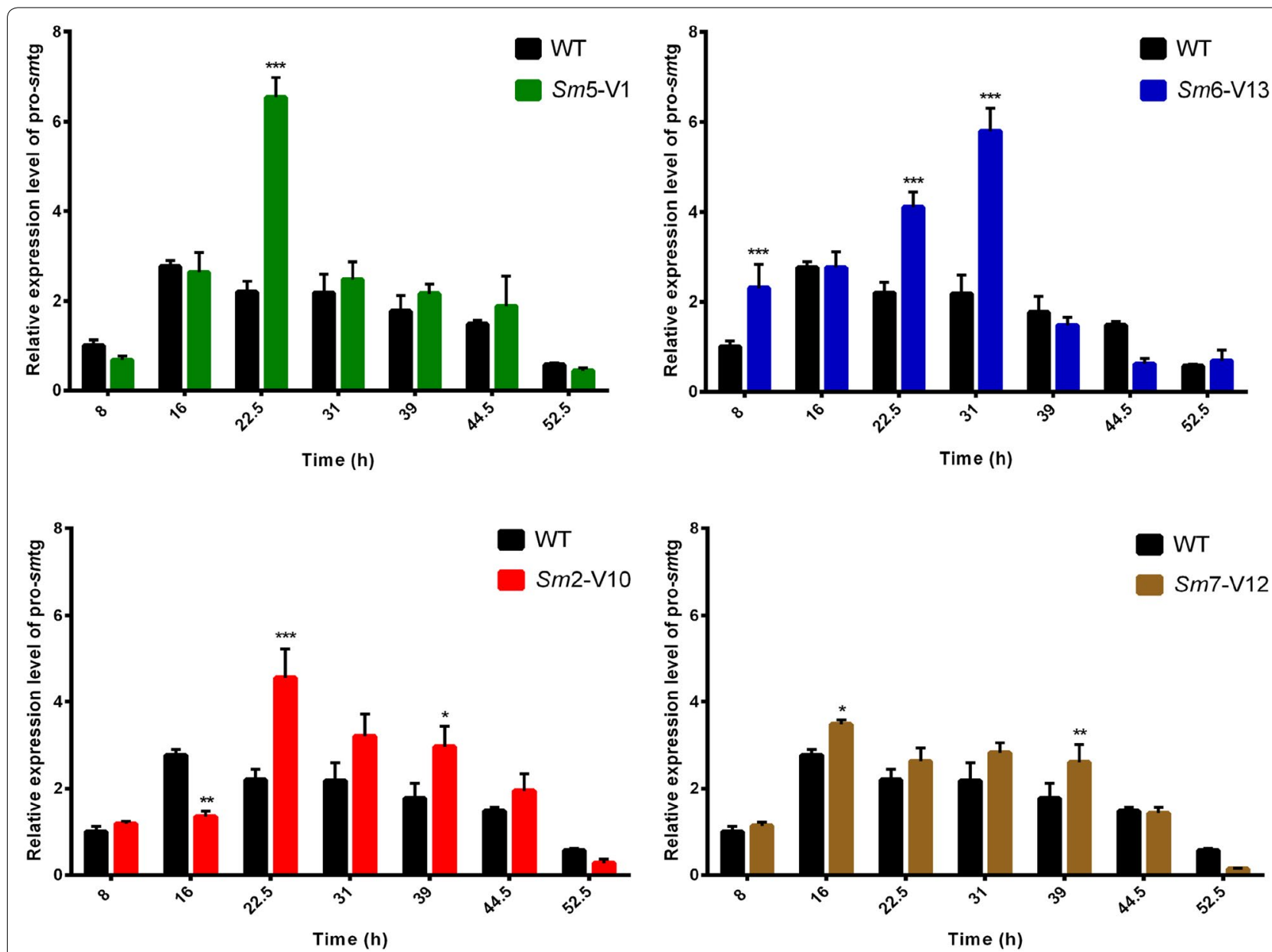

Fig. 4 Transcription analysis of pro-smtg gene by qRT-PCR. The pro-smtg transcription levels were detected after flask fermentation for different times in wild-type strain (WT) and mutants Sm5-V1, Sm6-V13, Sm2-V10, and Sm7-V12, which were normalized to that of 16S rRNA gene by the $2^{-\Delta \Delta C t}$ method. The experiments were performed in three replications 
study is of great importance for further investigation of metabolic changes caused by ARTP mutagenesis.

\section{Conclusions}

Iterative ARTP mutagenesis was applied to improve the TGase production in S. mobaraensis as a novel and efficient mutation tool. As a result, four mutants, Sm5-V1, Sm6-V13, Sm2-V10, and Sm7-V12, with increased TGase production by $27,24,24$, and $19 \%$, respectively, were identified after eight rounds of iterative mutagenesis. The best mutant Sm5-V1 showed an enhanced TGase production of $5.85 \mathrm{U} / \mathrm{mL}$. In addition, the results of sequence alignment and qRT-PCR revealed that the expression of TGase zymogen gene increased obviously under the ARTP treatment, while the gene sequence remained unchanged. The analysis of the target gene sequence as well as transcription level conducted in this study would provide a valuable guidance for further researches and applications of ARTP mutagenesis.

\section{Additional file}

Additional file 1. Additional information.

\section{Abbreviations}

ARTP: atmospheric and room-temperature plasma; TGase: transglutaminase; MTG: microbial transglutaminases; RT-PCR: reverse transcription PCR; qRT-PCR: quantitative real-time PCR.

\section{Authors' contributions \\ $Y J$ wrote the experiment; $Y J$ and $C Z$ conducted the experiment; $Y S$ and $H L$ helped to revise the manuscript; $Y J, C L$, and JX conceived the research; JP and $Y B$ provided experimental materials and guidance. All authors read and approved the final manuscript.}

\section{Author details}

1 State Key Laboratory of Bioreactor Engineering, East China University of Science and Technology, Shanghai 200237, People's Republic of China. 2 Shanghai Collaborative Innovation Center for Biomanufacturing Technology, East China University of Science and Technology, Shanghai 200237, People's Republic of China.

\section{Acknowledgements}

The authors are thankful to the Prof. Yonghong Wang's research group for providing the ARTP mutation breeding system as well as the operative skills to perform this research work.

\section{Competing interests}

The authors declare that the research was conducted in the absence of any commercial or financial relationships that could be construed as a potential competing interest.

\section{Availability of data and materials}

All data generated or analyzed during this study are included in the main manuscript file.

\section{Consent for publication}

The authors approved the consent for publishing the manuscript.

\section{Ethics approval and consent to participate}

All the authors have read and agreed the ethics for publishing the manuscript.

\section{Funding}

This work is financially sponsored by the National Natural Science Foundation of China (No. 21536004), Shanghai Commission of Science and Technology (No. 15JC1400403), and Shanghai Pujiang Program (No. 15PJ1401200).

\section{Publisher's Note}

Springer Nature remains neutral with regard to jurisdictional claims in published maps and institutional affiliations.

Received: 7 June 2017 Revised: 1 August 2017 Accepted: 5 August 2017 Published online: 12 August 2017

\section{References}

Duran R, Junqua M, Schmitter JM, Gancet C, Goulas P (1998) Purification, characterisation, and gene cloning of transglutaminase from Streptoverticillium cinnamoneum CBS 683.68. Biochimie 80:313-319

Grossowicz N, Wainfan E, Borek E, Waelsch H (1950) The enzymatic formation of hydroxamic acids from glutamine and asparagine. J Biol Chem 187:111-125

Guo T, Tang Y, Xi YL, He AY, Sun BJ, Wu H, Liang DF, Jiang M, Ouyang PK (2011) Clostridium beijerinckii mutant obtained by atmospheric pressure glow discharge producing high proportions of butanol and solvent yields. Biotechnol Lett 33:2379-2383

Hua XF, Wang J, Wu ZJ, Zhang HX, Li HP, Xing XH, Liu Z (2010) A salt tolerant Enterobacter cloacae mutant for bioaugmentation of petroleum- and saltcontaminated soil. Biochem Eng J 49:201-206

Kobayashi K, Suzuki SI, Izawa Y, Yokozeki K, Miwa K, Yamanaka S (1998) Transglutaminase in sporulating cells of Bacillus subtilis. J Gen Appl Microbiol 44:85-91

Kumar AK (2015) UV mutagenesis treatment for improved production of endoglucanase and $\beta$-glucosidase from newly isolated thermotolerant actinomycetes, Streptomyces griseoaurantiacus. Bioresour Bioprocess 2:22

Laroussi M (2005) Low temperature plasma-based sterilization: overview and state-of-the-art. Plasma Process Polym 2:391-400

Lu Y, Wang LY, Ma K, Li G, Zhang C, Zhao HX, Lai QH, Li HP, Xing XH (2011) Characteristics of hydrogen production of an Enterobacter aerogenes mutant generated by a new atmospheric and room temperature plasma (ARTP). Biochem Eng J 55:17-22

Martins IM, Matos M, Costa R, Silva F, Pascoal A, Estevinho LM, Choupina AB (2014) Transglutaminase: recent achievements and new sources. Appl Microbiol Biotechnol 98:6957-6964

Marx CK, Hertel TC, Pietzsch M (2008) Purification and activation of a recombinant histidine-tagged pro-transglutaminase after soluble expression in Escherichia coli and partial characterization of the active enzyme. Enzyme Microb Technol 42:568-575

Ren F, Chen L, Tong QY (2017) Highly improved acarbose production of Actinomyces through the combination of ARTP and penicillin susceptible mutant screening. World J Microbiol Biotechnol 33:16

Salis B, Spinetti G, Scaramuzza S, Bossi M, Jotti GS, Tonon G, Crobu D, Schrepfer $R$ (2015) High-level expression of a recombinant active microbial transglutaminase in Escherichia coli. BMC Biotechnol 15:84

Soares LHB, Assmann F, Ayub MAZ (2003) Purification and properties of a transglutaminase produced by a Bacillus circulans strain isolated from the Amazon environment. Biotechnol Appl Biochem 37:295-299

Tan J, Chu J, Wang YH, Zhuang YP, Zhang SL (2014) High-throughput system for screening of Monascus purpureus high-yield strain in pigment production. Bioresour Bioprocess 1:16

Wang Q, Feng LR, Wei L, Li HG, Wang L, Zhou Y, Yu XB (2014) Mutation breeding of lycopene-producing strain Blakeslea Trispora by a novel atmospheric and room temperature plasma (ARTP). Appl Biochem Biotechnol 174:452-460

Xu F, Jin HJ, Li HM, Tao L, Wang JP, Lv J, Chen SF (2012) Genome shuffling of Trichoderma viride for enhanced cellulase production. Ann Microbiol 62:509-515

Yokoyama K, Nio N, Kikuchi Y (2004) Properties and applications of microbial transglutaminase. Appl Microbiol Biotechnol 64:447-454 
Yurimoto H, Yamane M, Kikuchi Y, Matsui H, Kato N, Sakai Y (2004) The propeptide of Streptomyces mobaraensis transglutaminase functions in cis and in trans to mediate efficient secretion of active enzyme from methylotrophic yeasts. Biosci Biotechnol Biochem 68:2058-2069

Zhang X, Zhang XF, Li HP, Wang LY, Zhang C, Xing XH, Bao CY (2014) Atmospheric and room temperature plasma (ARTP) as a new powerful mutagenesis tool. Appl Microbiol Biotechnol 98:5387-5396

Zhang X, Zhang C, Zhou QQ, Zhang XF, Wang LY, Chang HB, Li HP, Oda Y, Xing XH (2015) Quantitative evaluation of DNA damage and mutation rate by atmospheric and room-temperature plasma (ARTP) and conventional mutagenesis. Appl Microbiol Biotechnol 99:5639-5646
Zhu Y, Rinzema A, Tramper J, Bol J (1995) Microbial transglutaminase-a review of its production and application in food processing. Appl Microbiol Biotechnol 44:277-282

Zotzel J, Keller P, Fuchsbauer HL (2003a) Transglutaminase from Streptomyces mobaraensis is activated by an endogenous metalloprotease. Eur J Biochem 270:3214-3222

Zotzel J, Pasternack R, Pelzer C, Ziegert D, Mainusch M, Fuchsbauer HL (2003b) Activated transglutaminase from Streptomyces mobaraensis is processed by a tripeptidyl aminopeptidase in the final step. Eur J Biochem 270:4149-4155

\section{Submit your manuscript to a SpringerOpen ${ }^{\circ}$ journal and benefit from:}

- Convenient online submission

- Rigorous peer review

- Open access: articles freely available online

- High visibility within the field

- Retaining the copyright to your article

Submit your next manuscript at $\boldsymbol{\nabla}$ springeropen.com 